\title{
Pattern of Contraceptive Used by Tribal Couples of Chattogram Hill Tract
}

\author{
Zafreen $\mathrm{F}^{1}$, Wahab MA ${ }^{2}$, Razzak MA ${ }^{3}$, Rahman $\mathrm{MH}^{4}$ \\ DOI: https:/ / doi.org/ 10.3329/ jafmc.v15i2.50825
}

\begin{abstract}
Introduction: Chattogram hill tract is the least economically developed area of Bangladesh where, education and health care facilities are hard to reach. Pattern of contraceptive use depends on couples' socio-cultural, education and economic condition.

Objective: To find out the pattern of contraceptive used by selected tribal couples of Guimara Upazila of Khagrachari District.

Materials and Methods: This descriptive cross-sectional study was conducted from October 2016 to March 2017 on 145 married women age ranging from 15 to 45 years reported to outpatient department of Border Guard Hospital, Guimara, Khagrachari were selected purposively after informed written consent. All the necessary data were collected in a pretested structured questionnaire by face to face interview.
\end{abstract}

Results: Among the 145 respondents highest $50.3 \%$ was in age group of $15-25$ years. Respondents' ethnicity was Marma $37.9 \%$, Tripura $38.6 \%$ and Chakma $23.5 \%$. Majority $52.4 \%$ of the respondents' profession was farming, $68.3 \%$ was illiterate and $55.9 \%$ had monthly family income less than five thousand Taka. Only $39.3 \%$ respondents were using various types of contraceptives. Among the ethnic groups 47.1 Chakma, 39.3\% Tripura and 34.5\% Marma respondents were using contraceptives. Among the contraceptive user, $93 \%$ were using temporary methods and only $7 \%$ using permanent methods. Among the contraceptives users oral contraceptive pill (OCP) was highest $56.1 \%$ followed by condom $15.8 \%$ and injectable $8.8 \%$. Respondents got information about contraceptives mostly from family planning workers $50.9 \%$ followed by relatives $19.3 \%$.

Conclusion: Majority of the tribal couple of this study population were not using any contraceptives. Those couple were using contraceptives among them OCP was most common. Appropriate measure should be taken to increase the contraceptive use rate by tribal couples of Chattogram Hill Tracts.

Key-words: Contraceptive methods, Tribal couples, Chattogram hill tract.

\section{Introduction}

Bangladesh is one of the most densely populated countries in the world with a high fertility rate ${ }^{1}$. Contraception is an essential method for reducing fertility rate ${ }^{2}$. Chattogram hill tract $(\mathrm{CHT})$ is the least economically developed area of Bangladesh where, education and health care facilities are hard to reach. Pattern of contraceptive use depends on couples' socio-cultural, education and economic condition ${ }^{3}$. In Bangladesh, modern contraceptive methods are easily available at all health care facilities including community clinics and family planning outreach centers, almost free of charge ${ }^{5}$. Family planning visitors routinely visit the married couples in rural communities. Various types of contraceptive methods are now available in the community to fulfill the aim of family planning 6 . Since different ethnic groups lives in $\mathrm{CHT}$ and they have different tradition. Communication from each house to other is difficult as well as education and economical status is lower than the other part of the country.

Methods of contraceptive can be classified into temporary including hormonal contraceptives, condoms, IUDs and implants and permanent methods including tubectomy for female and vasectomy for male 7 . In spite of availability of a wide range of contraceptives and mass media campaigns and information, education and communication programs, the population control remains a distant dream to achieve the target. Though birth control is the responsibility of both the partner and contraceptive methods for both men and women are available but women's contraceptive prevalence rates are higher than the men's in a developing society like Bangladesh. Reasons are related to socio-cultural status, family authority, economic freedom and education status of couple ${ }^{8}$. Contraceptive method choice is a fundamental indicator of quality of care in a family planning program 9 . The permanent method users are found less in number in comparison to people using temporary and long acting methods. Lack of knowledge of contraceptive methods or a source of supply and poor accessibility are the barriers that exist in developing countries ${ }^{10}$. Bangladesh has improved a lot in the field of birth control and contraceptive use but this improvement is not equal throughout the country. Chattogram hill tract is the least develop area of Bangladesh, where education rate is low and health care facilities are hard to reach. this study was designed to find out the prevalence of contraceptive used by the tribal couples of $\mathrm{CHT}$.

\section{Material and Methods}

This descriptive cross-sectional study was conducted from October 2016 to March 2017 among 145 married tribal women age ranging from 15 to 45 years reported to outpatient department of Border Guard Hospital, Guimara (BGHG), Khagrachari were selected purposively after informed written consent. All the necessary data were collected in a pretested structured questionnaire by face to face interview. Collected data were analyzed by SPSS for Windows 20.0 and presented as frequency and percentage.

\section{Results}

Among the 145 respondents highest number 73(50.3\%) was in age group of $15-25$ years Respondents' ethnicity was Marma $55(37.9 \%)$, Tripura 56(38.6\%) and Chakma 34(23.5\%). About 40(27.6\%) respondents were married for less than 5 years and 29(20.0\%) were married for more than 20 years. Majority of the respondents'

1. Dr Farzana Zafreen, MBBS, MPH, Associate Professor \& Head, Department of Community Medicine, Medical College for Women \& Hospital, Uttara, Dhaka (E-mail: farzana_zafreen@yahoo.com) 2. Lt Col Md Abdul Wahab, MBBS, MD, Associate Professor of Biochemistry, AFMC, Dhaka 3. Brig Gen Md Abdur Razzak, MBBS, MCPS, FCPS, APLAR Clinical Fellow Rheumatology, Chief Physician, CMH, Dhaka 4. Brig Gen Md Habibur Rahman, MBBS, FCPS, Professor and Head, Department of Medicine, AFMC, Dhaka. 
profession was farming 76(52.4\%), maximum 99(68.3\%) was illiterate and $81(55.9 \%)$ had monthly family income less than five thousand takas (Table-I). Only 57(39.3\%) respondents were using various types of contraceptives in contrary 88(60.7\%) were not using any contraceptives (Fig-1). Among the ethnic groups 47.1 Chakma, $39.3 \%$ Tripura and $34.5 \%$ Marma respondents were using contraceptives (Figure-2 \& Table-II). Among the contraceptive user $93 \%$ were using temporary methods and only $7 \%$ using permanent methods (Figure-3). Among the contraceptives users oral contraceptive pill (OCP) was highest $56.1 \%$ followed by condom $15.8 \%$ and injectable $8.8 \%$ (Table-III). Respondents got information about contraceptives mostly from family planning workers $50.9 \%$ followed by relatives 19.3\% and mass media 14.0\% (Table-IV).

Table-I: Socio-demographic characteristics of respondents ( $n=145$ )

\begin{tabular}{|l|l|c|c|}
\hline \multicolumn{2}{|c|}{ Characteristics } & Frequency & Percentage \\
\hline \multirow{4}{*}{ Age in years } & $15-25$ & 73 & 50.3 \\
\cline { 2 - 4 } & $26-35$ & 39 & 26.9 \\
\cline { 2 - 4 } & $36-45$ & 33 & 22.8 \\
\hline \multirow{4}{*}{ Ethnic group } & Marma & 55 & 37.9 \\
\cline { 2 - 4 } & Tripura & 56 & 38.6 \\
\cline { 2 - 4 } & Chakma & 34 & 23.5 \\
\hline \multirow{3}{*}{$\begin{array}{l}\text { Duration of } \\
\text { marriage } \\
\text { (years) }\end{array}$} & $1-5$ & 40 & 27.6 \\
\cline { 2 - 4 } & $6-10$ & 37 & 25.5 \\
\cline { 2 - 4 } & $11-20$ & 39 & 26.9 \\
\cline { 2 - 4 } & $>20$ & 29 & 20.0 \\
\hline \multirow{3}{*}{$\begin{array}{l}\text { Education } \\
\text { status }\end{array}$} & Iliterate & 99 & 68.3 \\
\cline { 2 - 4 } & Primary & 34 & 23.4 \\
\cline { 2 - 4 } & Secondary & 12 & 8.3 \\
\hline \multirow{3}{*}{ Occupation } & Housewife & 63 & 43.4 \\
\cline { 2 - 4 } & Farming & 76 & 52.4 \\
\cline { 2 - 4 } & Service & 6 & 4.2 \\
\hline \multirow{3}{*}{$\begin{array}{l}\text { Monthly family } \\
\text { income } \\
\text { (Taka) }\end{array}$} & $<5000$ & 81 & 55.9 \\
\cline { 2 - 4 } & $5000-10000$ & 47 & 32.4 \\
\cline { 2 - 4 } & $>10000$ & 17 & 11.7 \\
\hline \multirow{2}{*}{} & & & \\
\hline
\end{tabular}

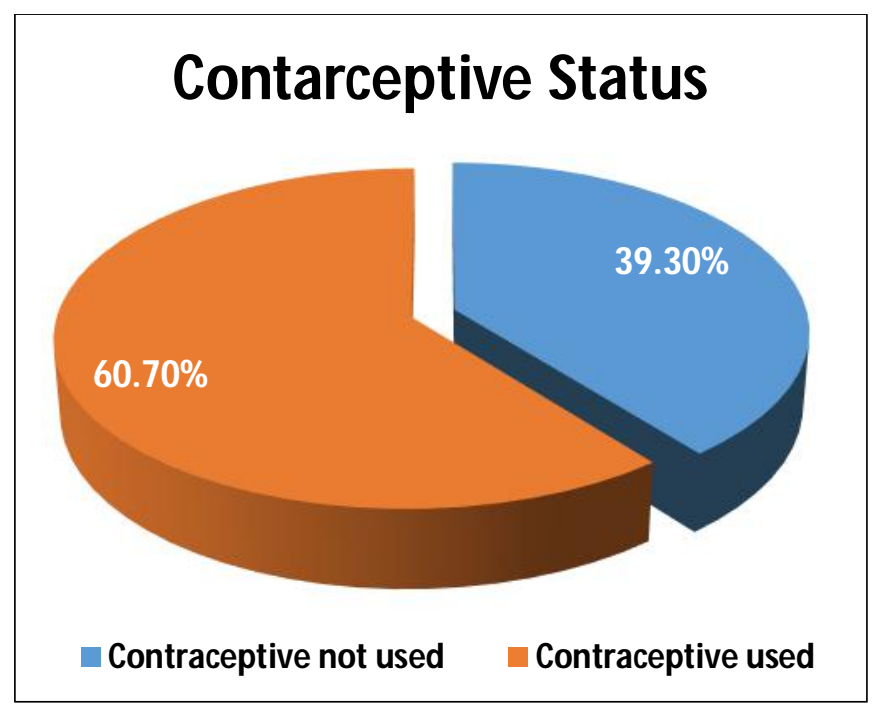

Figure-1: Contraceptive using status ( $n=145)$

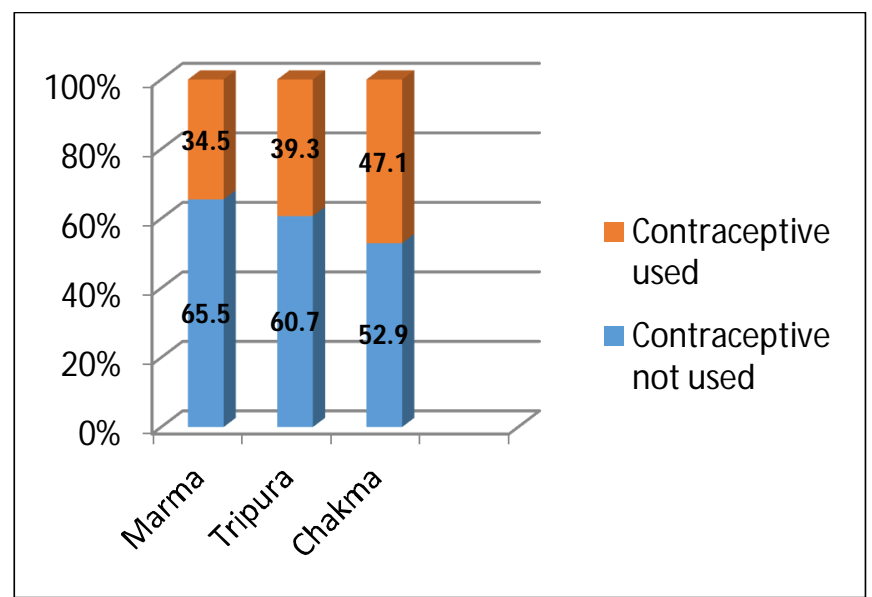

Figure-2: Contraceptive using status by ethnic group ( $n=145$ )

Table-II: Distribution of respondents by contraceptive status ( $n=145$ )

\begin{tabular}{|l|c|c|c|}
\hline \multicolumn{1}{|c|}{ Ethnic group } & Total & \multicolumn{2}{c|}{ Contraceptive used } \\
\hline Marma & 55 & 19 & 34.5 \\
\hline Tripura & 56 & 22 & 39.3 \\
\hline Chakma & 34 & 16 & 47.1 \\
\hline Total & 145 & 57 & 39.3 \\
\hline
\end{tabular}

\section{Types of Contraceptive Used}

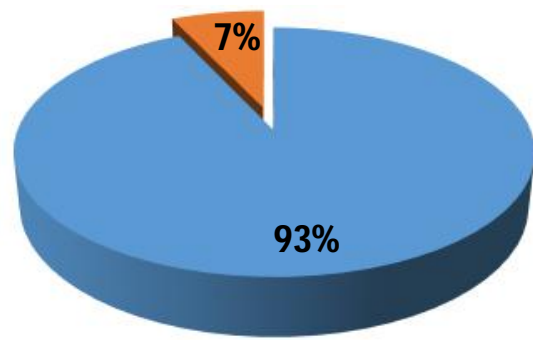

Temporary methods

Permanent methods

Figure-3: Distribution of respondents by the type of contraceptive methods used $(n=57)$

Table-III: Distribution of respondents by the type of contraceptive used $(n=57)$

\begin{tabular}{|c|c|c|c|}
\hline \multicolumn{2}{|c|}{ Type of contraceptives used } & Frequency & Percentage \\
\hline \multirow{6}{*}{$\begin{array}{l}\text { Temporary } \\
\text { methods }\end{array}$} & OCP & 32 & 56.1 \\
\hline & Condom & 9 & 15.8 \\
\hline & Injectable & 5 & 8.8 \\
\hline & Implant & 4 & 7.0 \\
\hline & IUDs & 3 & 5.3 \\
\hline & Total & 53 & 93.0 \\
\hline \multirow{3}{*}{$\begin{array}{l}\text { Permanent } \\
\text { methods }\end{array}$} & Tubectomy & 3 & 5.3 \\
\hline & Vasectomy & 1 & 1.8 \\
\hline & Total & 4 & 7.0 \\
\hline
\end{tabular}


Table-IV: Distribution of respondents by source of information about contraceptive $(n=57)$

\begin{tabular}{|l|c|c|}
\hline Source of information & Frequency & Percentage \\
\hline Family planning worker & 29 & 50.9 \\
\hline Mass media & 8 & 14.0 \\
\hline Husband & 3 & 5.3 \\
\hline Relatives & 11 & 19.3 \\
\hline Quacks & 4 & 7.0 \\
\hline Qualified doctors & 2 & 3.5 \\
\hline Total & 57 & 100 \\
\hline
\end{tabular}

\section{Discussion}

This descriptive cross sectional study was aimed at to find out the prevalence of contraceptive devices among 145 tribal females of Chattogram Hill Tract of Bangladesh. In this study, about $50.3 \%$ respondents were in age group of $15-25$ years which is consistent with similar study ${ }^{11}$. Ethnicity, education, occupation and monthly family income status was consistent with the demographic data of Khagrachari district2 2 .

In this study only $39.3 \%$ respondents were using different types of contraceptives and $60.7 \%$ were not using any contraceptives. Prevalence of contraceptive user found in this study was far below than the family planning bulletin data 2018. Among the contraceptive users $56.1 \%$ were using OCP, $15.8 \%$ using condom this finding was consistent with similar studies 7,13 but was not consistent with other studies 5 .9. In this study permanent method of contraceptive users were only $7 \%$ this findings were consistent with similar studies ${ }^{10,14}$. Most of the respondents got information about contraceptives from family planning workers or their relatives, this finding consistent with similar studies in Bangladesh ${ }^{11,12}$. In this study injectable, implant and IUD users were $8.8 \%, 7.0 \%$ and $5.3 \%$ respectively; these findings were consistent with similar studies ${ }^{6,10}$. From this study it revealed that male partners are not only taking less responsibility for contraceptive use but also some cases they are barring to use contraceptives.

\section{Conclusion}

Prevalence of contraceptive use among tribal couple in Chattogram Hill Tract is lower than the overall rate of Bangladesh. Male partners are not only taking less responsibility for contraceptive use but also some cases they are barring to use contraceptives. Appropriate measure should be taken to increase the contraceptive use rate so that total fertility can be controlled.

\section{References}

1. WHO. Women of South-East Asia: A Health profile. Women's health status Bangladesh (1998) South-East Asia region, New Delhi 2002.

2. NIPORT. Bangladesh: Demographic and Health Survey, 2014.

3. Health, Population and Nutrition Sector Development Program (2011-2016), Program Implementation Plan. In: MoH\&FW, Editor. Dhaka: Government of Bangladesh.

4. Mansur AMSA, Chowdhury S, Rezaul KM et al. Unmet needs of family planning and practice of family planning in a selected urban to rural migrated population of Dhaka city; Journal of family and reproductive health 2012; 6(3):115-22.

5. Chaudhury HR. Unmet need for contraception in South Asia: Levels, Trendsand Determinants. Asia Pacific Pop Journal 2001; 16(3):3-22.

6. Ferdousi SK, Jabbar MA, Et el. Unmet need of family planning among rural women in Bangladesh. J Dhaka Med Coll 2010; 19(1):11-5.

7. Qazi HA, Hashmi A, Raza SA et al. Contraceptive methods and factors associated with modern contraceptive in use, Journal of family and reproductive health 2010; 4(1):41-5.

8. Kabir A, Islam MN, Chowdhury AA et al. Unmet Need for Family Planning among Married Women: Experience from Rural and Urban Communities. Faridpur Med CollJ 2013; 8(1):26-30.

9. NIPORT. Mitra and Associates, and Macro International. Bangladesh Demographic and Health Surrvey, 2007; Preliminary report, Dhaka, Bangladesh.

10. Uddin ME, Ferdous Z. Gender of birth control method practice in sexual behavior in Bangladesh. Antrocom 2009; 5(2): 87-91.

11. Casterline JB and Sinding SW. Unmet need for family planning in developing countries and implications for population policy. Population and Development Review 2000; 26(4):691-723.

12. Pradhan J, Dwivedi R. Why Unmet Need for Family Planning Remains High in Bangladesh: A Community Level Analysis. J Women's Health Care 2015; 4:290.

13. Kamal N, Mohsena M. Twenty years of field visits by FP workers in Bangladesh: Are they still needed? The Journal of Family Welfare 2011; 57(1):10-7.

14. Sultana S, Jahan MS, Islam MM. Contraceptive acceptance among eligible couples residing in Rajshahi City Corporation. Journal of teachers Association 2007; 20(1):11-6. 